Zeszyty Naukowe Szkoły Głównej Gospodarstwa Wiejskiego

Ekonomika i Organizacja Gospodarki Żywnościowej nr 111, 2015: 71-80

Marzena Jeżewska-Zychowicz, Maria Królak

Katedra Organizacji i Ekonomiki Konsumpcji

Szkoła Główna Gospodarstwa Wiejskiego w Warszawie

\title{
Konsumencka percepcja nowych technologii stosowanych w produkcji żywności
}

\section{Wstęp}

Zmiany w preferencjach i zachowaniach nabywczych konsumentów, także duże wysycenie rynku zmusza producentów do projektowania i wprowadzania na rynek nowych produktów żywnościowych o podwyższonych walorach zdrowotnych, często wytworzonych za pomocą nowych technologii. Działania te mają na celu dostosowanie się do potrzeb i oczekiwań konsumentów i zwiększanie konkurencyjności przedsiębiorstwa [Siro i in. 2008, Barrena i Sánchez 2012].

Reakcje konsumentów na nowe produkty pojawiające się na rynku są warunkowane wieloma czynnikami, a jednym $\mathrm{z}$ nich jest postawa wyrażająca obawy oraz niechęć do ich zakupu, określana jako food neophobia [Pliner i Hobden 1992, Barrena i Sánchez 2012]. Postawa ta nie tylko wpływa na akceptację nieznanych wcześniej produktów, ale także na akceptację technologii stosowanych w ich produkcji [Ronteltap i in. 2007, Siegrist i in. 2007]. Do pomiaru tej postawy wykorzystywana jest Food Technology Neophobia Scale (FTNS) [Cox i Evans 2008], która może służyć do wyodrębniania segmentów konsumentów o zróżnicowanym poziomie neofobii, warunkującym akceptację żywności produkowanej z ich wykorzystaniem [Evans i in. 2010].

Poglądy zarówno na temat samej żywności, jak i technologii wykorzystywanych w jej produkcji mają duży udział w wyjaśnianiu decyzji konsumenckich dotyczących żywności [Ares i Gambaro 2007, Bruhn 2007, Vassalo i in. 2009]. $\mathrm{Z}$ dotychczasowych badań wynika, że dla konsumentów ważne są metody pro

\footnotetext{
*Badanie zostało wykonane w ramach Projektu Nr POIG.01.03.01-14-041/12 Bioprodukty, innowacyjne technologie wytwarzania prozdrowotnych produktów piekarskich i makaronu o obniżonej kaloryczności” współfinansowanego z Europejskiego Funduszu Rozwoju Regionalnego w ramach Programu Operacyjnego Innowacyjna Gospodarka.
} 
dukcji żywności, także żywności o zmodyfikowanych cechach żywieniowych [Cox i in. 2004]. Na przykład w przypadku produktów zbożowych konsumenci jako najbardziej akceptowane metody przetwarzania żywności wskazali tradycyjne krzyżowanie, następnie wzbogacanie, frakcjonowanie i fermentację [Dean $\mathrm{i}$ in. 2007]. Zgodnie z oczekiwaniami genetyczne modyfikacje były najmniej akceptowaną metodą [Finucane i Holup 2005]. Niemniej jednak Mucci i Hough [2003] stwierdzili, że stosowanie genetycznych modyfikacji produktu w celu poprawy jego walorów żywieniowych oceniane jest korzystnie, natomiast tylko modyfikacje w celu poprawy właściwości sensorycznych są oceniane negatywnie.

Zastosowanie różnych aplikacji technologicznych pozwala osiąnąć wiele korzyści, w tym wydłużyć okres przydatności żywności do spożycia, zwiększyć jej walory żywieniowe czy wygodę stosowania. Niemniej jednak akceptacja technologii stosowanych $\mathrm{w}$ produkcji żywności wśród konsumentów jest zróżnicowana [Cardello i in. 2007, Costa i in. 2000], niektóre z nich wywołują sprzeciw, $\mathrm{np}$. zastosowanie genetycznych modyfikacji, tym samym osiagane dzięki nim rezultaty mogą być przez konsumentów odrzucane. $Z$ badań wynika, że większość konsumentów charakteryzuje się stosunkowo niewielką wiedzą o technologiach stosowanych w produkcji żywności [Bruhn 2007], co może istotnie warunkować opinie na temat stosowania tych technologii w produkcji żywności [Cardello i in. 2007, Rollin i in. 2011].

Nowe technologie pomagają zrealizować korzyści poszukiwane przez konsumenta, ale produkty o wysokim stopniu przetworzenia wywołują u niektórych konsumentów różne obawy, zwłaszcza u tych, którzy z technologiami o niskim stopniu przetworzenia i ich efektami łączą większe walory zdrowotne żywności i równowagę $\mathrm{w}$ środowisku. Bardziej innowacyjni konsumenci są natomiast przekonani, że stosowane technologie mogą zmniejszyć ryzyko i dostarczyć korzyści wcześniej niedostępnych [Bruhn 2007].

Celem badania było poznanie postaw konsumentów wobec nowych technologii stosowanych w produkcji żywności.

\section{Metodyka badań własnych}

Badanie empiryczne zrealizowano w listopadzie 2013 roku w grupie ogólnopolskiej 1000 dorosłych konsumentów za pomocą metody wywiadów bezpośrednich ze wspomaganiem komputerowym (CAPI) z wykorzystaniem quasi standaryzowanego kwestionariusza wywiadu. Kryteria doboru próby uwzględniały reprezentatywność populacji ze względu na województwo, a następnie dobór miał charakter kwotowy z uwzględnieniem płci, wykształcenia oraz wielkości miejsca zamieszkania. Do wywiadu kwalifikowano jedynie osoby spełniające 
kryterium rekrutacyjne, czyli dokonywanie samodzielnych lub we współudziale zakupów żywności.

Narzędzie badawcze zawierało stwierdzenia tworzące skalę, na podstawie której oceniane są postawy badanych względem nowych technologii stosowanych w produkcji żywności (Food Technology Nephobia Scale - FTNS). Skala składa się z 13 stwierdzeń, które zostały przedstawione w tabeli 1, a odpowiedzi odzwierciedlające stopień zgodności respondenta z poszczególnymi stwierdzeniami były przedstawiane na 7-punktowej skali, gdzie ocena 1 oznacza nie zgadzam się, a ocena 7 - całkowicie zgadzam się [Cox i Evans 2008]. W kwestionariuszu zamieszczono również pytania dotyczące charakterystyki socjodemograficznej badanych osób.

Analizę statystyczną wykonano za pomocą pakietu IBM Statistics SPSS, wersja 21. Do analizy danych zastosowano analizę częstości, tabele krzyżowe oraz analizę czynnikową. Do stwierdzenia różnic istotnych statystycznie między zmiennymi wykorzystano test $\mathrm{Chi}^{2}$, przy poziomie istotności $\mathrm{p}<0,05$.

Zakres punktów ze skali FTNS wynosi 13-99, im większą liczbę punktów uzyska osoba, tym charakteryzuje się ona bardziej neofobiczną postawą względem nowoczesnych technologii [Cox i Evans 2008]. Miara FTNS w omawianym badaniu zawierała się w zakresie 19-91 pkt., wartość średnia wynosiła 58,25, a odchylenie standardowe 13,05.

Analizę czynnikową wykonano w celu wyznaczenia czynników głównych reprezentujących postawę badanych względem nowych technologii stosowanych w produkcji żywności, a także do potwierdzania przydatności poszczególnych stwierdzeń w dalszych analizach. Uzyskano potwierdzenie przydatności wszystkich stwierdzeń zawartych w FTNS (wartości ładunków czynnikowych powyżej 0,700). Wartość testu Kaiser-Meyer-Olkina wynosiła 0,922, a wartość testu Bartletta $-8053,91(\mathrm{df}=78 ; \mathrm{p}<0,001)$.

Dla każdego respondenta obliczono sumę ocen sformułowanych dla poszczególnych stwierdzeń tworzących Food Technology Neophobia Scale, następnie obliczono wartość średnią (X) i odchylenie standardowe (SD). Wskaźniki te wykorzystano do wyznaczenia zakresów trzech postaw względem nowych technologii stosowanych w produkcji żywności. Postawa pozytywna wobec tych technologii (suma minimalna - X-SD), określona jako postawa neofiliczna, mieściła się w zakresie punktów 19,00-45,20; postawa (X-SD - X+SD) została określona jako neutralna (zakres punktów 45,21-71,30); a postawę mieszczącą się w zakresie $\mathrm{X}+\mathrm{SD}$ - maksymalna suma określono jako postawę neofobiczną względem nowych technologii stosowanych $\mathrm{w}$ produkcji żywności (zakres punktów 71,31-91,0). Postawę neofiliczną reprezentowało $12,6 \%$ badanych, postawę neutralną $-71,3 \%$ i postawę neofobiczną $-16,1 \%$ badanej populacji. 
Tabela 1

Opinie badanych o nowych technologiach stosowanych w produkcji żywności

\begin{tabular}{|c|c|c|c|c|c|}
\hline $\begin{array}{l}\text { Stwierdzenia z Food Technology } \\
\text { Neophobia Scale (FTNS) }\end{array}$ & \begin{tabular}{|c|}
$\%$ \\
ocen \\
1 i $2^{*}$ \\
\end{tabular} & $\begin{array}{l}\% \\
\text { ocen } \\
6 \text { i } 7 \\
\end{array}$ & $\begin{array}{l}\text { Ocena } \\
\text { średnia }\end{array}$ & SD & Ładunki \\
\hline \multicolumn{6}{|c|}{ I składowa - Percepcja ryzyka i potrzeby stosowania nowoczesnych technologii } \\
\hline $\begin{array}{l}\text { Istnieje dużo smacznych produktów żywnościo- } \\
\text { wych i dlatego nie ma potrzeby wykorzystywania } \\
\text { nowych technologii do produkcji żywności }\end{array}$ & 11,1 & 29,1 & 4,54 & 1,58 & 0,754 \\
\hline $\begin{array}{l}\text { Korzyści wynikające z zastosowania nowych } \\
\text { technologii w produkcji żywności są często mocno } \\
\text { przereklamowane }\end{array}$ & 8,0 & 31,4 & 4,71 & 1,53 & 0,758 \\
\hline $\begin{array}{l}\text { Nowe technologie stosowane w produkcji żywno- } \\
\text { ści obniżają naturalne właściwości żywności }\end{array}$ & 8,4 & 31,5 & 4,66 & 1,56 & 0,795 \\
\hline $\begin{array}{l}\text { Nie ma sensu próbowanie nowych produktów } \\
\text { żywnościowych, ponieważ te które spożywam sa } \\
\text { wystarczająco dobre }\end{array}$ & 12,7 & 23,9 & 4,32 & 1,60 & 0,769 \\
\hline $\begin{array}{l}\text { Nowe produkty żywnościowe nie sa zdrowsze } \\
\text { od tradycyjnej żywności }\end{array}$ & 9,9 & 28,6 & 4,57 & 1,56 & 0,764 \\
\hline $\begin{array}{l}\text { Nowe technologie stosowane w produkcji żywno- } \\
\text { ści to coś, do czego nie jestem przekonana }\end{array}$ & 8,7 & 29,3 & 4,60 & 1,52 & 0,857 \\
\hline $\begin{array}{l}\text { Społeczeństwo nie powinno uzależniać się od } \\
\text { technologii, aby rozwiązać istniejące problemy } \\
\text { żywnościowe }\end{array}$ & 7,0 & 30,9 & 4,72 & 1,52 & 0,813 \\
\hline $\begin{array}{l}\text { Nowe technologie stosowane w produkcji żywno- } \\
\text { ści moga mieć długofalowy negatywny wpływ na } \\
\text { środowisko }\end{array}$ & 7,2 & 31,2 & 4,64 & 1,51 & 0,826 \\
\hline $\begin{array}{l}\text { Zbyt szybkie włączanie nowych technologii do } \\
\text { produkcji żywności może być ryzykowne }\end{array}$ & 6,8 & 33,9 & 4,76 & 1,53 & 0,839 \\
\hline $\begin{array}{l}\text { Nowe technologie stosowane w produkcji żywno- } \\
\text { ści moga mieć długofalowy negatywny wpływ na } \\
\text { zdrowie }\end{array}$ & 8,3 & 28,8 & 4,71 & 1,51 & 0,834 \\
\hline \multicolumn{6}{|c|}{ II składowa - Prozdrowotny wybór żywności i rola mediów } \\
\hline $\begin{array}{l}\text { Produkty żywnościowe wytworzone za pomoca } \\
\text { nowych technologii nie pomoga ludziom w prawi- } \\
\text { dłowym odżywianiu się }\end{array}$ & 14,4 & 14,2 & 3,96 & 1,43 & 0,858 \\
\hline $\begin{array}{l}\text { Nowe technologie nie pozwolą ludziom sprawo- } \\
\text { wać większej kontroli nad wyborem żywności }\end{array}$ & 15,2 & 13,8 & 4,05 & 1,43 & 0,875 \\
\hline $\begin{array}{l}\text { Media zazwyczaj nie dostarczaja wyważonych } \\
\text { i bezstronnych opinii o nowych technologiach sto- } \\
\text { sowanych w produkcji żywności }\end{array}$ & 18,6 & 16,6 & 4,02 & 1,62 & 0,708 \\
\hline
\end{tabular}

*Skala 7 - punktowa; 1 - całkowicie nie zgadzam się; 7 - całkowicie zgadzam się. 


\section{Postawy badanych względem nowych technologii stosowanych w produkcji żywności}

Opinie badanych na temat stwierdzeń opisujących ich postawy względem nowych technologii stosowanych w produkcji żywności, tworzące Food Technology Neophobia Scale (FTNS), wykazały neutralny lub raczej negatywny stosunek do tych technologii, co potwierdzają wartości średnie ocen (tab. 1). Udział ocen wyrażających brak zgodności ze stwierdzeniem (oceny 1 i 2 ) był mniejszy niż wyrażających zgodność (oceny 6 i 7), z wyjątkiem trzech stwierdzeń. Ponad 3-krotnie więcej osób potwierdziło, że korzyści ze stosowania nowych technologii są przereklamowane oraz technologie te obniżają naturalne właściwości żywności. Ponadto dotyczyło to braku przekonania do tych technologii, braku konieczności ich stosowania w celu rozwiązania istniejących problemów żywnościowych, obaw związanych $\mathrm{z}$ długofalowym negatywnym wpływem na środowisko i na zdrowie oraz ryzyka związanego ze zbyt szybkim wprowadzaniem nowych technologii do produkcji żywności. Obawy konsumentów związane z nowoczesnymi technologiami i ryzyko z nimi związane zostały wykazane także w innych badaniach [Evans i Cox 2006, Cardello i in. 2007, Ronteltap i in. 2007]. Podobny odsetek osób (ok. 15\%) reprezentował zarówno pozytywne, jak i negatywne opinie o możliwości wykorzystania produktów żywnościowych wytworzonych za pomocą nowych technologii w realizacji prawidłowego odżywiania się oraz w sprawowaniu kontroli nad wyborem żywności. Nieco więcej osób postrzegało media jako źródło bezstronnych opinii o nowych technologiach stosowanych w produkcji żywności, ale wartość średnia ocen $(4,02)$ wyrażała opinię neutralną w tej kwestii (tab. 1). Z innych badań wynika, że postawy względem nowoczesnych technologii stosowanych w produkcji żywności są zróżnicowane, ale z przewagą negatywnych postaw [Ronteltap i in. 2007, Cox i Evans 2008], co znalazło potwierdzenie w uzyskanych wynikach.

Wyniki analizy czynnikowej zostały przedstawione w tabeli 1 . Wyodrębnione zostały dwa czynniki główne wyjaśniające $65,3 \%$ wariancji, pierwsza składowa wyjaśnia 49,8\% wariancji, podczas gdy druga - 15,5\% wariancji. Początkowe wartości czynników wynosiły odpowiednio: 6,48 i 2,02.

Pierwszy czynnik był reprezentowany przede wszystkim przez stwierdzenia dotyczące ryzyka związanego z zastosowaniem nowoczesnych technologii i potrzeby ich wykorzystania w produkcji żywności (wartości współczynników korelacji $>0,700$ ). Drugi czynnik obejmował opinie dotyczące aspektów zdrowotnych żywności oraz oceny informacji zamieszczanych w mediach (tab. 1).

W przypadku stwierdzeń wyrażających ryzyko związane ze spożywaniem takiej żywności oraz brak potrzeby stosowania nowoczesnych technologii (czyn- 
nik 1) wartość średnia mieściła się w zakresie 4,32-4,72. Natomiast wartość średnia opinii dotyczących możliwości wykorzystania żywności wytworzonej za ich pomocą do lepszego zbilansowania diety oraz kontroli nad wyborem żywności (czynnik 2) wynosiła ok. 4,00, a więc była opisana oceną ,,ani się zgadzam, ani się nie zgadzam" (tab. 1).

\section{Rola czynników socjodemograficznych w warunkowaniu postaw względem nowych technologii}

Postawy względem nowych technologii stosowanych w produkcji żywności były zróżnicowane po uwzględnieniu płci, wykształcenia, wieku i opinii o dochodzie. Postawy pozytywne (neofiliczne) względem nowych technologii stosowanych w produkcji żywności były reprezentowane przez większy odsetek kobiet, osób lepiej wykształconych, osób w wieku 26-36 lat, ale również w wieku 36-55 lat. Wśród osób z postawą neofiliczną było więcej osób, które określiły dochód swojej rodziny jako całkowicie niewystarczający oraz bardzo satysfakcjonujący (,stać nas na wszystko i możemy zaoszczędzić”). Postawy neofobiczne były reprezentowane przez większy odsetek mężczyzn, osób z relatywnie niższym wykształceniem oraz starszych respondentów (tab. 2).

Podobnie jak w innych badaniach [Bruhn 2007, Fell i in. 2009] potwierdzono istotne różnice $\mathrm{w}$ postawach względem technologii stosowanych $\mathrm{w}$ produkcji żywności po uwzględnieniu takich cech socjodemograficznych, jak płeć, wykształcenie i wiek. Uzyskane wyniki dotyczące płci nie zostały potwierdzone w badaniu Fell i innych [2009], w którym okazało się, że kobiety były mniej pozytywnie nastawione i dostrzegały mniej korzyści z wykorzystania nowych technologii niż mężczyźni, co wskazuje na większe nasilenie neofobii.

\section{Podsumowanie}

Postawy badanych względem nowych technologii stosowanych w produkcji żywności były zróżnicowane, $\mathrm{z}$ tendencją do reprezentowania postaw neutralnych i negatywnych. Potwierdzono w ten sposób rezultaty badań realizowanych w innych populacjach [Evans i Cox 2006, Cardello i in. 2007, Ronteltap i in. 2007]. Obawy konsumentów i odczuwane ryzyko z nimi związane sprzyjały bardziej neofobicznym postawom, podczas gdy bardziej pozytywne opinie dotyczyły możliwości wykorzystania żywności w ten sposób wytworzonej do zbilansowania diety oraz kontrolowania wyboru żywności. 


\section{Tabela 2}

Struktura populacji z uwzględnieniem postaw względem nowych technologii stosowanych w produkcji żywności i charakterystyki socjodemograficznej badanych [\%]

\begin{tabular}{|c|c|c|c|}
\hline \multirow{2}{*}{ Cechy populacji } & \multicolumn{3}{|c|}{ Postawy względem nowych technologii } \\
\hline & neofiliczna & neutralna & neofobiczna \\
\hline Cała populacja & 12,6 & 71,3 & 16,1 \\
\hline $\begin{array}{l}\text { Płeć }(\%, p=0,007) \\
\text { Kobiety } \\
\text { Mężczyźni }\end{array}$ & $\begin{array}{l}14,5 \\
10,3\end{array}$ & $\begin{array}{l}72,3 \\
70,1\end{array}$ & $\begin{array}{l}13,2 \\
19,6\end{array}$ \\
\hline $\begin{array}{l}\text { Wykształcenie }(\% ; p=0,041) \\
\text { Podstawowe } \\
\text { Zasadnicze zawodowe } \\
\text { Średnie } \\
\text { Wyższe }\end{array}$ & $\begin{array}{c}8,0 \\
11,9 \\
12,2 \\
15,9\end{array}$ & $\begin{array}{l}67,0 \\
69,7 \\
75,1 \\
69,0\end{array}$ & $\begin{array}{l}25,0 \\
18,4 \\
12,7 \\
15,1\end{array}$ \\
\hline $\begin{array}{l}\text { Wiek }(\% ; p<0,001) \\
25 \text { lat i mniej } \\
26-35 \text { lat } \\
36-45 \text { lat } \\
41-55 \text { lat } \\
56-65 \text { lat } \\
\text { Więcej niż } 65 \text { lat }\end{array}$ & $\begin{array}{l}11,4 \\
20,0 \\
15,1 \\
14,1 \\
3,6 \\
8,9\end{array}$ & $\begin{array}{l}78,9 \\
66,9 \\
72,3 \\
72,4 \\
72,1 \\
57,1\end{array}$ & $\begin{array}{c}9,8 \\
13,1 \\
12,7 \\
13,4 \\
24,4 \\
33,9\end{array}$ \\
\hline $\begin{array}{l}\text { Opinia o dochodzie }(\% ; p=0,001) \\
\text { Jest całkowicie niewystarczający } \\
\text { Pozwala zaspokoić jedynie podsta- } \\
\text { wowe potrzeby } \\
\text { Stać nas na niektóre, ale nie } \\
\text { wszystkie wydatki } \\
\text { Stać nas na wszystko } \\
\text { Stać nas na wszystko i możemy } \\
\text { zaoszczędzić }\end{array}$ & $\begin{array}{c}22,5 \\
10,2 \\
12,1 \\
9,6\end{array}$ & $\begin{array}{l}61,3 \\
71,5 \\
70,6 \\
81,3 \\
55,6\end{array}$ & $\begin{array}{c}16,3 \\
18,3 \\
17,4 \\
9,0\end{array}$ \\
\hline
\end{tabular}

Uzyskane wyniki stwarzają duże możliwości ich praktycznego wykorzystania na różnych etapach życia produktu, od momentu powstawania koncepcji produktu do jego pojawienia się na rynku, włączając strategie marketingowe oraz sposób informowania konsumenta o produkcie i jego jakości. Potwierdzenie różnic w postawach względem nowych technologii stosowanych w produkcji żywności, także po uwzględnieniu charakterystyki socjodemograficznej konsumentów, skłania do podejmowania właściwych decyzji w procesie informowania o produkcie. Eksponowanie informacji o zastosowanej metodzie produkcji, co może wydawać się zachętą do nabywania produktu, w kontekście uzyskanych wyników należy interpretować odwrotnie, czyli w kategoriach bariery nabywania. Aby te ograniczenia zminimalizować należy rozważyć możliwość zastosowania komunikatów ukierunkowanych na wzrost wiedzy o technologiach, w tym o korzyściach wynikających z ich zastosowania. Większa wiedza konsumentów 
na ten temat może sprzyjać bardziej pozytywnym postawom wobec technologii, tym samym zmniejszać nasilenie postaw neofobicznych. Niemniej jednak sama ocena postaw wobec nowych technologii stosowanych w produkcji żywności, bez zbadania ich związku z decyzjami nabywczymi, nie jest wystarczająca do potwierdzenia słuszności przyjętych założeń. Konieczne jest zatem kontynuowanie badań z wykorzystaniem Food Technology Neophobia Scale w połączeniu $\mathrm{z}$ badaniem zachowań konsumentów na rynku żywności.

\section{Literatura}

ARES G., GÁMBARO A., 2007: Influence of gender, age and motives underlying food choice on perceived healthiness and willingness to try functional foods, Appetite, vol. 49 , s. $148-158$.

BARRENA R., SÁNCHEZ M., 2012: Neophobia, personal consumer values and novel food acceptance, Food Quality and Preference, vol. 27, s. 72-84.

BRUHN C.M., 2007: Enhancing consumer acceptance of new processing technologies, Innovative Food Science and Emerging Technology, vol. 8, s. 555-558.

CARDELLO A.V., SCHUTZ H.G., LESHER L.L., 2007: Consumer perceptions of foods processed by innovative and emerging technologies: A conjoint analytic study, Innovative Food Science and Emerging Technology, vol. 68, s 73-83.

COSTA-FONT M., GIL J.M., TRAIL B.W., 2008: Consumer acceptance, valuation of and attitudes towards genetically modified food: Review and implications for food policy, Food Policy, vol. 33, s. 99-111.

COX D.N., EVANS G., 2008: Construction and validation of a psychometric scale to measure consumers'fears of novel food technologies: the food technology neophobia scale, Food Quality and Preference, vol. 19, s. 704-710.

COX D.N., KOSTER A., RUSSELL C.G., 2004: Predicting intentions to consume functional foods and supplements to offset memory loss using an adaptation of protection motivation theory, Appetite, vol. 33, s. 55-64.

DEAN M., SHEPHERD R., ARVOLA A., VASSALLO M., WINKELMANN M., CLAUPEIN E., LÄHTEENMÄKI L., RAATS M.M., SABA A., 2007: Consumer perceptions of healthy cereal products and production methods, Journal of Cereal Science vol. 46, s. $188-196$.

EVANS G., COX D.N., 2006: Australian consumers'antecedents of attitudes towards foods produced by novel technologies, British Food Journal, vol. 108, s. 916-930.

EVANS G., KERMARREC C., SABLE T., COX D.N., 2010: Reliability and predictive validity of the Food Technology Neophobia Scale, Appetite, vol. 54, s. 390-393.

FELL D., WILKINS D.S., KIVINEN E., AUSTIN A., FERNANDEZ M., 2009: An evidence review of public attitudes to emerging food technologies, A Brook Lyndhurst Report for the Food Standards Agency, s.17-29.

FINUCANE M.L., HOLUP J.L., 2005: Psychosocial and cultural factors affecting the perceived risk of genetically modified food: an overview of the literature, Social Science \& Medicine, vol. 60, s. 1603-1612. 
MUCCI A., HOUGH G., 2003: Perceptions of genetically modified foods by consumers in Argentina, Food Quality and Preference, vol. 15, s. 43-51.

PLINER P., HOBDEN K., 1992: Development of a scale to measure the trait of food neophobia in humans, Appetite, vol. 19, s. 105-120.

ROLLIN F., KENNEDY J., WILLS J., 2011: Consumers and new food technologies, Trends in Food Science and Technology, vol. 22, pp. 99-111.

RONTELTAP A., VAN TRIJP J.C.M., RENES R.J., FREWER L.J., 2007: Consumer acceptance of technology based food innovations: lessons for the future of nutrigenomics. Appetite, vol. 49, s. 1-17.

SIEGRIST M., KELLER C., KASTENHOLZ H., FREY S., WICK A., 2007: Lay peoples and experts perceptions of nanotechnology hazards. Risk Analysis, vol. 27, s. 59-65.

SIRO I., KAPOLNA E., KAPOLNA B., LUGASI A., 2008: Functional food. Product development, marketing and consumer acceptance - A review, Appetite, vol. 51, s. 456-461.

VASSALLO M., SABA A., ARVOLA A., DEAN M., MESSINA F., WINKELMANN M., CLAUPEN E., LÄHTEENMÄKI L., SHEPHERD R., 2009: Willingness to use functional breads. Applying the Health Belief Model across four European countries, Appetite, vol. 52, s. 452-460.

\section{Abstrakt}

Celem badania było poznanie postaw konsumentów wobec nowych technologii stosowanych w produkcji żywności, które mierzono za pomocą skali Food Technology Neophobia Scale. Badanie ankietowe przeprowadzono w 2013 roku w ogólnopolskiej grupie 1000 konsumentów. Do analizy danych zastosowano analizę częstości, tabele krzyżowe oraz analizę czynnikową. Do stwierdzenia różnic istotnych statystycznie między zmiennymi wykorzystano test Chi2, przy poziomie istotności $\mathrm{p}<0,05$.

Wykazano neutralny lub raczej negatywny stosunek do nowych technologii stosowanych w produkcji żywności. Bardziej pozytywne postawy były reprezentowane przez kobiety i osoby w wieku 26-35 lat, natomiast bardziej negatywne przez mężczyzn, osoby starsze oraz osoby z niższym wykształceniem. Eksponowanie informacji o zastosowanej metodzie produkcji w przypadku osób z negatywną, także z neutralną postawą wobec stosowanych technologii może być barierą w nabywaniu produktów żywnościowych, co wskazuje na ostrożne wykorzystywanie tej informacji w komunikatach marketingowych lub prowadzenie edukacji konsumenckiej w tym zakresie.

Słowa kluczowe: konsument, metody produkcji żywności, Food Technology Neophobia Scale 


\section{Consumer perception of novel food technologies}

\section{Abstract}

The aim of the study was to investigate consumers' attitudes to novel technologies used in food production. They were measured using a scale of Food Technology Neophobia Scale. The survey was conducted in 2013 in a nationwide group of 1000 consumers. For data analysis the frequency analysis, cross tables and factor analysis were used. To determine statistically significant differences between the variables, Chi-square test was used at $p<0.05$. It revealed neutral or even negative consumers' attitude to novel technologies used in food production. More positive attitudes were represented by women and those aged 26-35, while more negative ones by men, the elderly and people with lower levels of education. It can be concluded that exposing information about the method of food production can be a barrier to purchasing food products within people with negative or even neutral attitudes towards novel technologies. A monitored use of this information in marketing communications and/or conducting consumer education in this area is needed.

Key words: consumer, food technology, Food Technology Neophobia Scale 